\title{
Reactive Lymphocyte to Lymphocyte Ratio Measurement
}

National Cancer Institute

\section{Source}

National Cancer Institute. Reactive Lymphocyte to Lymphocyte Ratio Measurement. NCI Thesaurus. Code C74654.

The determination of the ratio of reactive lymphocytes compared to all lymphocytes present in a sample. The measurement may be expressed as a ratio or percentage. 